\title{
CONTRIBUIÇÃO DO SENPE PARA DIVULGAÇÃO CIENTÍFICA
}

Ao historiarmos os diversos eventos e atividades de divulgação da produção científica em enfermagem, realizadas pela $A B E n$, percebe-se que, nesta trajetória existe a presença implícita das dimensões da pesquisa, do ensino e da assistência.

Sem dúvida, esta tríade consolida-se como pedra fundamental na construção do perfil profissional, por não ser mais a pesquisa, domínio do saber acadêmico e, por outro lado, o intra-muros assistencial abre suas comportas para oferecer e oferecer-se à possibilidade da articulação assistência / academia, pois cada vez mais um contingente maior de enfermeiros, ditos "do campo", ingressam nos programas de pósgraduação.

A academia, por sua vez, tem sentido a força que representa a parceria com o campo no desenvolvimento do processo ensinoaprendizagem e na integração da pesquisa e assistência.

Acessar a pesquisa, contextualizar a academia na sua realidade social, unir esforços para a formação e qualificação profissional, são alguns dos fenômenos que vêm favorecendo a formação de núcleos de pesquisa multiprofissionais, interinstitucionais e interdisciplinares.

O Seminário Nacional de Pesquisa em Enfermagem - SENPE tem representado o espaço para que ocorram as discussões sobre os mais variados temas acerca da pesquisa, do ensino da pesquisa, da articulação pesquisa/assistência, além de propiciar reflexões sobre as interfaces da pesquisa e os programas de pós-graduação. 
No ano de 1997, o $9^{\circ}$ SENPE realizado em Vitória - ES, abriu a discussão sobre o impacto do conhecimento produzido em enfermagem na sociedade e outros temas que remetem à reflexão do papel social das instituições de ensino, tanto para a profissão como para a comunidade. Confirmou a evolução e amadurecimento dos enfermeiros na sua forma de pensar e realizar pesquisa, com vistas à possibilidade de integração na prática profissional, que reflete-se aqui, retratados pelos trabalhos publicados neste número da Revista Brasileira de Enfermagem.

O SENPE e demais eventos e atividades desenvolvidas pela ABEn como meios de incentivo e divulgação da produção científica em enfermagem, devem vir a firmar-se, não como instrumentos de informação, mas como agentes de transformação dos profissionais e da profissão. 